\title{
Effects of Tryptophan Depletion on the Performance of an Iterated Prisoner's Dilemma Game in Healthy Adults
}

\author{
Richard M Wood', James K Rilling ${ }^{2}$, Alan G Sanfey ${ }^{2}$, Zubin Bhagwagar ${ }^{3}$ and Robert D Rogers*,' \\ 'University Department of Psychiatry, University of Oxford, Oxford, UK; ${ }^{2}$ Departments of Anthropology, Psychiatry and Behavioral Sciences, \\ Emory University, Atlanta, GA, USA; ${ }^{3}$ Department of Psychiatry, Yale University, New Haven, CT, USA
}

\begin{abstract}
Adaptive social behavior often necessitates choosing to cooperate with others for long-term gains at the expense of noncooperative behaviors giving larger immediate gains. Although little is know about the neural substrates that support cooperative over noncooperative behaviors, recent research has shown that mutually cooperative behavior in the context of a mixed-motive game, the Prisoner's Dilemma (PD), is associated with increased neural activity within reinforcement circuitry. Other research attests to a role for serotonin in the modulation of social behavior and in reward processing. In this study, we used a within-subject, crossover, double-blind design to investigate performance of an iterated, sequential PD game for monetary reward by healthy human adult participants following ingestion of an amino-acid drink that either did $(T+)$ or did not $(T-)$ contain I-tryptophan. Tryptophan depletion produced significant reductions in the level of cooperation shown by participants when playing the game on the first, but not the second, study days. This effect was accompanied by a significantly diminished probability of cooperative responding given previous mutually cooperative behavior. These data suggest that serotonin plays a significant role in the acquisition of socially cooperative behavior in human adult participants, and suggest novel hypotheses concerning the serotonergic modulation of reward information in socially cooperative behavior in both health and psychiatric illness.

Neuropsychopharmacology (2006) 3 I, 1075-1084. doi:I 0. I038/sj.npp. I 300932; published online I I January 2006
\end{abstract}

Keywords: Prisoner's Dilemma; serotonin; reciprocal cooperation; social function; aggression; reward

\section{INTRODUCTION}

Mutually cooperative behavior among individuals is an integral part of greater-ape society, yet there has been relatively limited research into the nature of the neural substrates supporting social cooperation in human and non-human species. The Prisoner's Dilemma (PD) offers a tractable laboratory measure of social cooperation based upon reciprocal altruism which can be used to advance this area experimentally (Trivers, 1971, 1985): two players make choices associated with certain pay-offs (represented by a 'pay-off matrix'; see below). The pattern of choices made can lead to an equal sharing or an unequal sharing of the pay-offs (favoring one player or the other), thereby allowing players to display cooperation or selfishness. This model has been used extensively by researchers from many disciplines to explore the emergence of cooperation in

\footnotetext{
*Correspondence: Dr RD Rogers, Department of Psychiatry, University of Oxford, Warneford Hospital, Oxford, Oxfordshire OX3 7JX, UK, Tel: + 441865226 399, Fax: + 441865793 I0I,

E-mail: robert.rogers@psych.ox.ac.uk

Received 23 December 2004; revised 21 July 2005; accepted 22 August 2005

Online publication: 9 September 2005 at http://www.acnp.org/citations/ Npp0909050406/0/default.pdf
}

evolutionary contexts (Axelrod, 1984; Axelrod and Hamilton, 1981), individual differences in competitive and exploitative strategies during reciprocal interactions (Pruitt and Kimmel, 1977), and to identify factors that promote or inhibit cooperation in diverse experimental and naturalistic settings (Axelrod, 1984; Boone et al, 2002; Sheldon, 1999).

Rilling et al (2002) used functional magnetic resonance imaging (fMRI) to investigate regional changes in bloodoxygenation-level-dependent response (BOLD) associated with socially cooperative behavior in an iterated PD game (viz., a game which is played several consecutive times or 'rounds' with the same partner). Mutually cooperative outcomes (in which both players chose to cooperate: CC) were associated with increased BOLD within the orbitofrontal cortex compared to mixed outcomes (in which one of the two players chose to cooperate, while the other chose to defect: $\mathrm{CD}$ or DC) and mutual defection outcomes (in which both players chose to defect: DD). Although this was the case when players believed they were playing with a human partner or a computer, mutual cooperation was associated with greater activation in the rostral anterior cingulate cortex and anteroventral striatum specifically when participants believed they were playing with a human partner. These neural systems receive dopamine projections from the midbrain and are known to be involved 
in reward and the processing of motivationally significant information (Robbins and Everitt, 1996), suggesting that socially cooperative behavior is supported by activity within reinforcement pathways (Moskowitz and Cote, 1995). A follow-up study using a one-shot PD paradigm in which participants played a new partner on each round confirmed this hypothesis by demonstrating increased BOLD within subcallosal anterior cingulate cortex, anteroventral striatum, and medial orbitofrontal cortex with mutually cooperative outcomes (Rilling et al, 2004).

Observations in several species indicate a role for serotonin in the modulation of prosocial behavior. Investigation of both peripheral and central indices of serotonin function have shown negative associations with violent and aggressive behavior in rhesus monkeys (Higley et al, 1992, 1996) and human clinical samples (Brown et al, 1979; Virkkunen et al, 1994), as well as positive associations with socially affiliative behaviors (such as grooming and approach) (Raleigh et al, 1981). Pharmacological interventions that increase serotonergic activity also attest to a prominent role in important aspects of social behavior and aggression (for a discussion, see Fuller, 1996). The selective serotonin reuptake inhibitor (SSRI), fluoxetine, increases affiliative behaviors in rodents (Knutson and Panksepp, 1996), while each of fluoxetine, quipazine (a 5- $\mathrm{HT}_{1}$ and $5-\mathrm{HT}_{2}$ receptor agonist), and the amino-acid serotonin precursor, l-tryptophan, have been found to increase affiliative behaviors and decrease nonsocial behaviors (such as vigilance and avoidance) in primates (Raleigh et al, 1985). Additional information about these effects has been provided by observations that fluoxetine and l-tryptophan increase the social dominance of subdominant vervet males in the absence of the alpha male, while interventions that antagonise serotonin (eg the $5-\mathrm{HT}_{2 \mathrm{C}}$ receptor antagonist, cyproheptadine, and chronic treatment with fenfluramine) prevent the emergence of dominance under these conditions (Raleigh et al, 1991).

In humans, major depressive disorder is widely accepted as involving altered serotonin function and is characterized by relatively poor social functioning (Fossi et al, 1984; Weissman, 2000). Consistent with this finding, antidepressant medications that enhance serotonergic function have been shown to increase affiliative behaviors, including verbal and nonverbal positive communication in depressed patients, sometimes independently of effects on depressed mood (Dubini and Polin, 1997), and can reduce hostile sentiment and violent outbursts in impulsive clinical samples (Coccaro and Kavoussi, 1997).

Despite this, experimental investigation of the role of serotonin in the social behavior of human participants has been limited. Chronic l-tryptophan intake has been found to both increase dominant behaviors, and decrease quarrelsomeness, in everyday interactions (Moskowitz et al, 2001), while the SSRI, paroxetine, has been found to increase affiliative gestures towards a partner during completion of a puzzle task after 1 but not 4 weeks of treatment (Knutson et al, 1998). More formally, Tse and Bond (2002a,b) have examined the effects of chronic treatment with the SSRI, citalopram, and the selective noradrenergic reuptake inhibitor, reboxetine, on the performance of an amended PD game involving the division of pay-offs between the two players and communication with the playing partner.
Chronic citalopram was associated with increased choices of the more generous pay-offs and increased affiliative messages sent to the playing partner (Tse and Bond, 2002a). In a similar study, reboxetine increased cooperation in the PD game, while citalopram sustained emotional expression of speech when speaking to a socially withdrawn partner (Tse and Bond, 2002b). Summarizing the above results, increasing serotonin activity appears to change indirect measures of social function in healthy human adults, and may increase affiliative gestures in dyadic interactions. However, there is little information about the effects of reducing serotonin on cooperative behavior in mixedmotive games, such as a true iterated PD, where the gains and losses for one player depend upon effective reciprocal exchanges with a social partner. We sought to investigate this issue in the present study.

We used rapid tryptophan depletion to restrict the availability of l-tryptophan for serotonin synthesis in healthy human participants in order to explore subsequent changes on performance of an iterated $\mathrm{PD}$ game for monetary reward. This methodology has shown to be an effective way of temporarily reducing serotonin activity in both animal and humans (Biggio et al, 1974; Carpenter et al, 1998), with evidence of cognitive effects in healthy participants without a history of mood disorder (Park et al, 1994; Rogers et al, 1999; Moore et al, 2000). The starting point for our study was the accumulating evidence that serotonin plays a role in modulating the various aspects of reward processing (Aronson et al, 1995; Redgrave and Horrell, 1976; Sasaki-Adams and Kelley, 2001) mediated by circuitry encompassing orbitofrontal and rostral cingulate cortices, and ventral striatum (Robbins et al, 1989). We wished to test the hypothesis that reducing serotonergic modulation in healthy participants would reduce the number of cooperations and increase the number of defections in an iterated PD game, perhaps by interfering with activity within reinforcement-related circuitry associated with mutually cooperative behavior.

\section{MATERIALS AND METHODS}

The study was approved by the Oxfordshire Psychiatry Research Ethics Committee, UK. All participants gave written informed consent.

\section{Subjects}

A total of 24 healthy adults (12 males; 12 females) participated. Previous research has shown that tryptophan depletion in participants with a history of mood disorder can reinstate dysphoria (Moore et al, 2000). Therefore, participants were carefully examined by an experienced psychiatrist $(\mathrm{ZB})$ to ensure that none of the following exclusion criteria were met: (i) major physical illness, (ii) current or previous DSM-IV major mood disorder as assessed by a SCID-I interview (First et al, 2002), and (iii) current or previous substance abuse. Participants with a family history of mood disorder were not excluded. There was no restriction on the phase of menstrual cycle in female participants. Verbal IQ was estimated with the National Adult Reading Test (Nelson, 1982). 


\section{Design}

The study consisted of a within-subject, crossover, doubleblind design. Each participant ingested an amino-acid drink on 2 study days, separated by not less than 1 week. One drink contained $l$-tryptophan $(\mathrm{T}+)$, the other drink did not $(\mathrm{T}-)$. The order of these treatments was counterbalanced across the participant group. A total of 12 participants underwent the $\mathrm{T}+$ treatment first and the $\mathrm{T}-$ treatment second (six male and six female) $(\mathrm{T}+/ \mathrm{T}-)$. A total of 12 participants underwent these treatments in the reverse order (six male and six female) $(\mathrm{T}-/ \mathrm{T}+)$.

\section{Materials}

Amino acids were supplied by SHS International Ltd. The amounts of each for male and female participants, respectively, were $l$-alanine $(5.5 \mathrm{~g} ; 4.58 \mathrm{~g}), l$-arganine $(4.9 \mathrm{~g}$; $4.08 \mathrm{~g}), \quad$-cystine $(2.7 \mathrm{~g} ; 2.25 \mathrm{~g})$, glycine (3.2 g; $2.67 \mathrm{~g})$, l-isoleucine ( $8.0 \mathrm{~g} ; 6.67 \mathrm{~g})$, l-leucine (13.5 g; $11.25 \mathrm{~g})$, l-lysine monohydrochloride $(11.0 \mathrm{~g} ; 9.17 \mathrm{~g}), \quad$-methionine $(3.0 \mathrm{~g}$; $2.5 \mathrm{~g}$ ), histidine (3.2 g; $2.67 \mathrm{~g})$; l-phenylalinine (5.7 g; $4.75 \mathrm{~g})$, l-proline (12.2 g; $10.17 \mathrm{~g}), \mathrm{l}$-serine $(6.9 \mathrm{~g} ; 5.75 \mathrm{~g}), \mathrm{l}$-threonine (6.5 g; $5.42 \mathrm{~g})$, l-tyrosine (6.9 g; $5.75 \mathrm{~g})$, l-valine ( $8.9 \mathrm{~g} ; 7.42 \mathrm{~g})$. The $\mathrm{T}+$ drink contained $l$-tryptophan $(2.3 \mathrm{~g} ; 1.92 \mathrm{~g})$. The unpleasant taste of the drinks was masked using $5 \mathrm{~g}$ flavor sachets. Each sachet consisted of citric acid (or malic acid), flavorings (lemon-and-lime, cherry-and-vanilla, or grape fruit), and artificial sweetener. Each sachet contained approximately 15 calories, and $1.3 \mathrm{~g}$ of carbohydrate.

\section{Procedure}

Participants followed a low-protein diet (less than $20 \mathrm{~g}$ ) the day before each study day. Participants attended the laboratory at 0830 hours. Blood samples were taken to obtain baseline levels of plasma total $l$-tryptophan. Participants then drank the amino-acid drink over a 30-min period. Some participants reported transitory nausea and tiredness. Participants were given a low-protein lunch (less than $2 \mathrm{~g}$ ). At $5 \mathrm{~h}$ after consuming the amino-acid drink $(+5 \mathrm{~h})$, a second blood sample was taken. Participants then completed the PD game.

Participants completed self-report measures of state positive and negative affect (PANAS; Watson et al, 1988) and validated visual analog scales of aggression (VAS; Bond and Lader, 1974) at baseline and $+5 \mathrm{~h}$. Participants also completed psychometric assessments of trait aggression using the Buss-Perry Aggression Questionnaire (AQ; Buss and Perry, 1992). The AQ provides subscales for physical and verbal aggression, hostility, and anger. The VAS was used to assess effects of tryptophan depletion on participants' mood, while the AQ was used to assess whether effects on social cooperation involved differences in trait aggression.

The iterated, sequential PD game. The iterated, sequential PD used in the study was adapted from that reported by Rilling et al (2002). The game was presented on a computer that had connecting cables going into the laboratory wall, facilitating the deception that the computer was networked to a different computer in another room. Before playing the game, each participant was introduced to a gender-matched 'partner' - in reality, an experimenter-confederate. It was explained to the participant that his/her computer was networked to a computer in another room in which their partner would play. The experimenter left to take the confederate to their room, returning a few minutes later to talk the participant through the $\mathrm{PD}$ game instructions. In fact, the confederate's choices were made by the computer, running a predetermined strategy of tit-for-tat (see below).

On each round of the PD game, the participant viewed a $2 \times 2$ matrix that displayed the pay-off matrix for that round (see Figure 1). The four squares of this pay-off matrix defined four possible outcomes: both players cooperate (CC); the participant cooperates but the partner defects (CD), the participant defects but the partner cooperates (DC), and both players defect (DD). The payoffs for the outcomes were constructed such that $\mathrm{DC}>\mathrm{CC}>\mathrm{DD}>\mathrm{CD}$, and $C C>(C D+D C) / 2$ (2). Specifically, if the participant and partner cooperated (CC), both would receive $20 \mathrm{p}$. If the participant defected while the partner cooperated (DC), the participant would earn $30 \mathrm{p}$, and the partner nothing; and vice versa (CD). If both players defected (DD), both would receive $10 \mathrm{p}$.

The participant's partner always chose first (ie the game was sequential). If the partner cooperated, the upper row of the matrix was highlighted in yellow. If the partner defected, the lower row was highlighted in yellow. After this, the participant responded with his own choice. If he/she cooperated, the left column was highlighted; if he/she defected, the right column was highlighted. Consequently, the combination of the partner's and the participant's choices specified the outcome of the round. The participant pressed the ' $\mathrm{C}$ ' key on the computer keyboard to indicate a cooperative response, and the ' $\mathrm{D}$ ' to indicate a defection response. Before starting, four training trials demonstrated the four possible choice combinations; the participant was also shown a table showing the total earnings arising through the four possible choice outcomes over the course of 20 rounds (see Table 1 ).

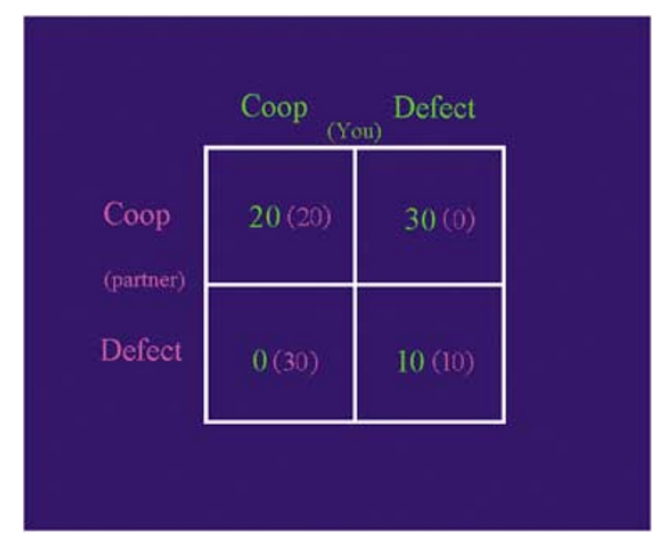

Figure I Payoff matrix for the four outcomes in the iterated, sequential Prisoner's Dilemma (PD) game. The participant's choices ('You') are listed atop columns and the partner's choices ('partner'; in fact, a computer program playing tit-for-tat) are listed aside the rows. The payoffs for each player, depending upon both players' choices, are shown within each square; green = participant's and pink= partner's). 
Table I Monetary Payoffs for Four Different Strategies Over the Course of the Iterated, Sequential Prisoner's Dilemma (PD) Game Consisting of 20 Rounds

\begin{tabular}{lcc}
\hline Strategies & You & Partner \\
\hline Both you and your partner cooperate each round & $400 p$ & $400 p$ \\
Your partner cooperates and you defect each round & $600 p$ & $0 p$ \\
Your partner defects and you cooperate each round & $0 p$ & $600 p$ \\
Both you and your partner defect each round & $200 p$ & $200 p$ \\
\hline
\end{tabular}

'You' = participant; 'Partner' = computer program playing tit-for-tat.

Participants played two separate PD games, each consisting of 20 rounds. The procedure contained two manipulations. First, the computer started the first game by choosing to cooperate but started the second game by choosing to defect. Second, after its first choice in both games, the computer followed a strict tit-for-tat strategy, always mimicking the responses of the participants on the previous round. Participants were thoroughly debriefed about the deception at the end of the study; all indicated that they had believed that they had been playing the PD game with a real human partner (ie the confederate) rather than a computer program.

\section{Statistics}

The dependent measures for the PD game were as follows: (i) the proportion of rounds on which participants chose to cooperate ('proportionate choice'); (ii) the deliberation time (in milliseconds) taken to make a cooperative or a defection choice; (iii) the 'conditional probability' of cooperating specified as the proportion of rounds on which participants cooperated following each of the four possible outcomes (CC, CD, DC, DD) on the immediately previous round.

Differences in age, estimated verbal IQ, and psychometric measures of self-report trait affect and aggression were analyzed by analysis of variance (ANOVA) with treatment order across the two study days $(\mathrm{T}+/ \mathrm{T}-$ and $\mathrm{T}-/ \mathrm{T}+)$ and gender as between-subject factors.

Proportionate choice of cooperative responses were analyzed with repeated measures ANOVAs with gender, treatment order as between-subject factors, and treatment $(\mathrm{T}+v s \mathrm{~T}-)$ and game $(1$ vs 2$)$ as within-subject factors. The reaction times (ms) for cooperative and defection responses were averaged together to give mean deliberation times and submitted to the same analysis as the proportionate choice data. Plasma tryptophan, state positive affect, state negative affect (PANAS), and state aggression (VAS) were analyzed with repeated measures ANOVAs with gender and treatment order as between subject-factors and treatment $(\mathrm{T}+$ $v s \mathrm{~T}-$ ) and time (baseline $v s+5 \mathrm{~h}$ ) as within-subject factors. (The 13 VAS subscales were included in order to assess whether the performance of the $\mathrm{PD}$ games following tryptophan depletion might be attributable to short-term changes in aggression. We did not correct for multiple comparisons when analyzing this data in order to highlight any such changes that might be relevant to the interpreta- tion of the data from the PD games.) Where the effects of the $\mathrm{T}-$ and $\mathrm{T}+$ treatments were different on the first and second study days, as indicated by significant two-way interactions between treatment and treatment order, dependent measures were subject to supplementary ANOVAs for each study day separately (to investigate simple interaction effects), with gender and treatment $(\mathrm{T}+v s \mathrm{~T}-)$ as two between-subject factors and game as a single withinsubject factor.

\section{RESULTS}

\section{Demographic and Trait Psychometrics}

Participants' mean age and verbal IQ were $27.04 \pm 1.49$ (SE) and $113.87 \pm 1.43$. There were no significant differences between the age or estimated IQs of those participants who completed the $\mathrm{T}+/ \mathrm{T}-$ treatment order $(27.89 \pm 2.26$ years and $112 \pm 1.98)$ and those who completed the $\mathrm{T}-/ \mathrm{T}+$ order $(26.20 \pm 2.00$ and $116 \pm 1.98)(F s(1,20)<2.35)$. Similarly, the two groups were matched for trait positive affect $(36.83 \pm 1.52$ vs $33.92 \pm 1.26 ; \mathrm{F}(1,20)=2.45)$, trait negative affect $(15.33 \pm 1.80 v s 13.25 \pm 0.70 ; \mathrm{F}(1,20)=1.14)$, total selfreport aggression $(62 \pm 2.45$ vs $66.18 \pm 4.14 ; \mathrm{F}<1.00)$, physical aggression $(14.25 \pm 0.90$ vs $17.09 \pm 1.88 ; \mathrm{F}(1,15)=$ $1.31)$, verbal aggression $(15.00 \pm 0.46$ vs $16.09 \pm 0.63$; $\mathrm{F}(1,15)=1.61)$, anger $(14.38 \pm 0.98$ vs $16.36 \pm 1.27 ; \mathrm{F}(1,15)=$ $1.15)$, and hostility $(18.38 \pm 1.21$ vs $16.64 \pm 1.30 ; \mathrm{F}(1,15)=$ 1.04). (For technical reasons, scores from the AQ (Buss and Perry, 1992) were unavailable for four participants who completed the $\mathrm{T}+/ \mathrm{T}-$ treatment order and for one participant who completed the $\mathrm{T}-/ \mathrm{T}+$ treatment order.)

\section{Plasma Tryptophan Levels}

As expected (Moore et al, 2000), total plasma tryptophan was reduced between baseline and $+5 \mathrm{~h}$ after the $\mathrm{T}-$ treatment $(12.44 \pm 0.68$ vs $1.92 \pm 0.27 \mu \mathrm{g} / \mathrm{ml})$ but increased after the $\mathrm{T}+$ treatment $(13.01 \pm 0.51$ vs $30.27 \pm 2.31 \mu \mathrm{g} / \mathrm{ml})$ $(\mathrm{F}(1,12)=123.43, p<0.0001)$. Analysis of simple effects confirmed that the difference in plasma tryptophan following the $\mathrm{T}-$ and $\mathrm{T}+$ treatments was significant at $+5 \mathrm{~h}$ $(\mathrm{F}(1,14)=134.67, p<0.0001)$.

\section{The Iterated, Sequential PD Game}

Treatment with the $\mathrm{T}$ - drink produced different kinds of effects on cooperative behavior on the 2 study days as evidenced by a significant two-way interaction between treatment and treatment order $(\mathrm{F}(1,20)=4.68, p<0.05)$. Statistical analysis of each study day separately demonstrated that the $\mathrm{T}-$ treatment was associated with significantly fewer cooperative responses than the $\mathrm{T}+$ treatment on day $1(\mathrm{~F}(1,20)=6.67, p<0.05)$ (see Figure 2 ), but a slightly increased number of such responses on day 2 $(\mathrm{F}(1,20)=2.63) \quad$ (Figure 2). Pair-wise tests showed that participants who underwent the $\mathrm{T}-$ treatment on day 1 showed a significant increase in cooperative responses after the $\mathrm{T}+$ treatment on day $2(0.50 \pm 0.07$ to $0.64 \pm 0.08$; $t($ two-tailed $)=2.26, \mathrm{df}=11, p<0.05)$, while participants who underwent the $\mathrm{T}+$ treatment on day 1 showed no significant change in cooperative responses after the 
$\mathrm{T}$ - treatment on day $2(0.73 \pm 0.05$ to $0.80 \pm 0.04 ; t$ (twotailed) $=-0.98, \mathrm{df}=11, p<0.35)$.

Overall, there was a trend for all participants to make more cooperative responses on the first game of 20 rounds than the second game of 20 rounds $(0.74 \pm 0.05 v s$ $0.59 \pm 0.06), \quad(F(1,20)=3.49, p=0.08)$. There were no significant differences between male and female participants in the proportion of cooperative responses $(0.68 \pm 0.06 v s$ $0.65 \pm 0.06$, respectively; $\mathrm{F}<1.0)$. There were no significant interactions involving treatment, gender, and game.

Treatment with the $\mathrm{T}-$ drink affected participants' deliberation times differently on the first and second study days, as evidenced by a two-way interaction between treatment and treatment order $(\mathrm{F}(1,20)=15.42, p<0.005)$.

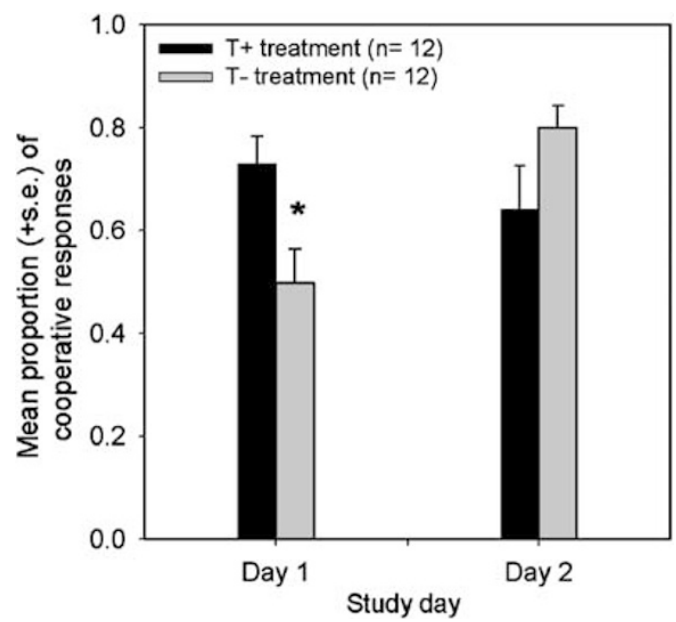

Figure 2 Mean proportion of cooperative choices of healthy participants who drank an amino-acid drink containing l-tryptophan $(T+)$ treatment and participants who drank an amino-acid drink not containing /-tryptophan ( $T$ - treatment) on the first and second study days. $* F(1,20)=6.67$, $p<0.05$.
However, analysis of each study day separately showed that the deliberation times following the $\mathrm{T}-$ and $\mathrm{T}+$ treatments did not differ significantly on day $1(3249 \pm 421 \mathrm{~ms} v \mathrm{~s}$ $2995 \pm 387 \mathrm{~ms}$, respectively) $(\mathrm{F}<1.00)$ or day $2(2337 \pm$ $279 \mathrm{~ms}$ vs $2042 \pm 208 \mathrm{~ms} ; \mathrm{F}<1.00)$. Mean deliberation times in the first game of 20 rounds were not significantly different from those in the second game $(2860 \pm 268 v s$ $2452 \pm 190 \mathrm{~ms})(\mathrm{F}(1,20)=2.94)$. Male participants did not significantly differ from female participants in their deliberation times $(2756 \pm 359$ vs $2557 \pm 197 \mathrm{~ms})(\mathrm{F}<1.00)$. There were no other significant interactions involving treatment, gender, and game.

Conditional probabilities of cooperative responses were defined as the proportion of trials on which participants made a cooperative choice given one of the four outcomes (CC, CD, DC, and DD) on the previous round of the game. On the first study day, the T- participants exhibited a significantly reduced conditional probability of a cooperative response given a mutual cooperative outcome on the previous round compared to the $\mathrm{T}+$ treatment (see Figure $3 ; \mathrm{F}(1,22)=4.35, p<0.05)$; no other differences in the conditional probability of cooperative responses were significant (all Fs $\leqslant 1.07$ ). On the second day, the $\mathrm{T}$ - treatment produced a slightly increased conditional probability of a cooperative response given a mutual cooperative outcome on the previous round compared to the $\mathrm{T}+$ treatment; this effect was not significant (Figure 3; $\mathrm{F}(1,22)=2.42)$.

\section{Self-Report Mood}

Overall, state positive affect was significantly reduced between baseline and $+5 \mathrm{~h}(\mathrm{~F}(1,20)=15.88, p<0.005)$, but no more so after the $\mathrm{T}-$ treatment $(31.29 \pm 1.42 \mathrm{vs}$ $28.96 \pm 1.47)$ compared to the $\mathrm{T}+$ treatment $(30.42 \pm 1.61 \mathrm{vs}$ $28.08 \pm 1.54)(\mathrm{F}<1.00)$. State negative affect did not change markedly between baseline and $+5 \mathrm{~h}(\mathrm{~F}(1,20)=2.29)$ after either the $\mathrm{T}$ - treatment $(12.71 \pm 0.94 v s 12.46 \pm 1.01)$ or $\mathrm{T}+$

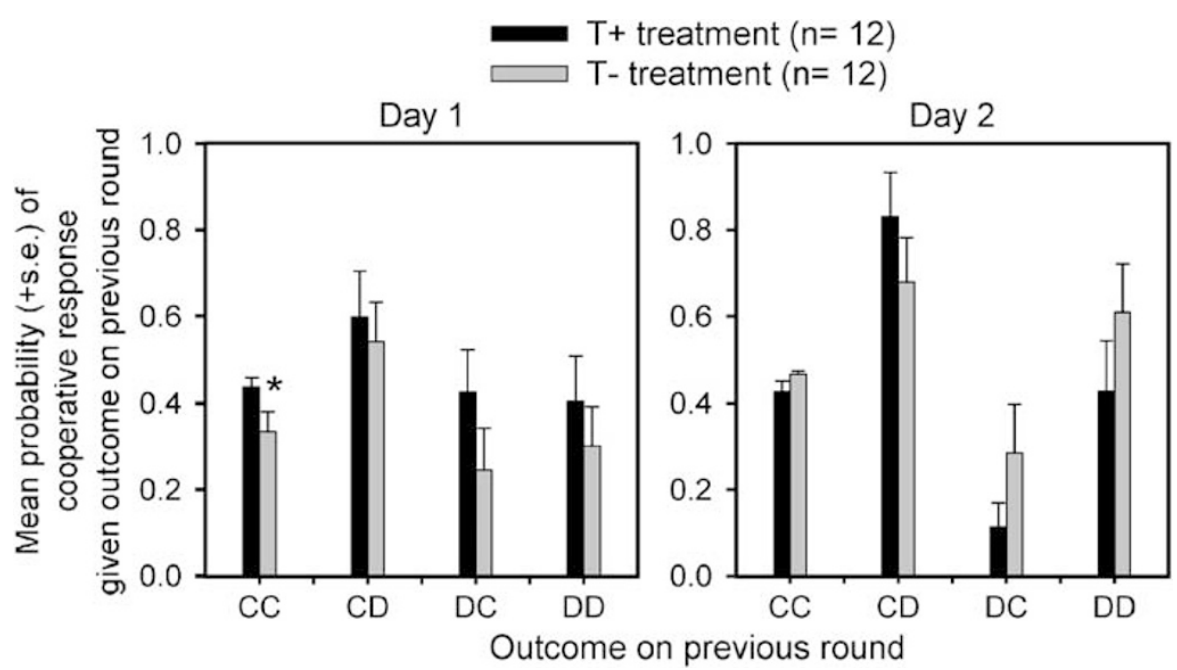

Figure 3 The conditional probability of making a cooperative choice given the four possible outcomes of the previous round in participants who drank an amino-acid drink containing I-tryptophan $(\mathrm{T}+)$ and in participants who drank an amino-acid drink not containing I-tryptophan ( $(T-)$ on the first and second study days $(C C=$ participant cooperates-partner cooperates, $C D=$ participant cooperates-partner defects, $D C=$ participant defects-partner cooperates, $\mathrm{DD}=$ participant defects-partner defects). $*=F(I, 2 I)=4.352, p<0.05$. 
treatment $(13.54 \pm 1.02$ vs $12.63 \pm 0.69)(\mathrm{Fs}<1.00)$. There were no significant differences in the state positive or negative affect of the $\mathrm{T}+$ and $\mathrm{T}-$ participants at baseline or $+5 \mathrm{~h}$ on either study day 1 or day 2 (all Fs $<1.00$; see Table 2). Entering state positive and negative affect at $+5 \mathrm{~h}$ on day 1 as covariates did not abolish the significant reduction in cooperative responses associated with the $\mathrm{T}-$ compared to $\mathrm{T}+$ treatments $(\mathrm{F}(1,18)=6.70$, $p<0.05)$.

\section{Self-Report Measures of State Aggression}

Overall, self-reported annoyance was significantly decreased after the $\mathrm{T}-$ compared to the $\mathrm{T}+$ treatment $(21.77 \pm 2.62 \mathrm{vs}$ $26.04 \pm 3.49)(F(1,20)=4.88, p<0.05)$; self-reported disgust was also reduced after the $\mathrm{T}-$ treatment compared to the $\mathrm{T}+$ treatment $(21.81 \pm 2.74$ vs $29.10 \pm 3.64)(\mathrm{F}(1,20)=5.48$, $p<0.05)$. Comparisons of ratings at $+5 \mathrm{~h}$ on study day 1 , taken just before playing the $\mathrm{PD}$ game, revealed that rebelliousness was significantly lower following the $\mathrm{T}-$ compared to $\mathrm{T}+$ treatment $(\mathrm{F}(1,20)=5.83, p<0.05)$; state furiousness showed a similar trend $(\mathrm{F}(1,20)=3.48$, $p=0.08)$. There were no other significant treatment-related differences in state aggression ratings at baseline or $+5 \mathrm{~h}$ on either study day (see Table 2).

\section{DISCUSSION}

The iterated PD has been used extensively by researchers in social psychology, economics, and game theory to model social relationships involving reciprocal altruism (Axelrod, 1984; Axelrod and Hamilton, 1981; Trivers, 1971, 1985). These results demonstrate that healthy adult participants who ingested an amino-acid drink lacking l-tryptophan ( $\mathrm{T}$ - treatment) showed a pattern of reduced cooperative responses on an iterated, sequential PD game compared to participants who drank a tryptophan-balanced drink ( $\mathrm{T}+$ treatment) on the first, but not second, day of the study (Figure 2). Additionally, the conditional probability of a cooperative response given a mutually cooperative outcome on the previous round of the game was similarly and significantly diminished (Figure 3). Consequently, these findings suggest that temporary reduction of central serotonin actitivity, achieved by manipulation of $l$-tryptophan, impairs the ability of healthy adults to learn (or acquire) a pattern of cooperative behavior in the context of a validated laboratory measure of reciprocal cooperation.

We acknowledge that the above pattern of data may reflect the influence of uncontrolled factors such as family history of mood disorder and, in the female participants, phase of menstrual cycle that might have interacted with tryptophan depletion to compromise cooperative behavior while playing the PD game. However, importantly, the reduced cooperative responses associated with the $\mathrm{T}-$ treatment on the first study day are not attributable to, or secondary to, temporary changes in mood. Consistent with previous studies (Moore et al, 2000), our participants, who did not include any with a history of mood disorder, did not report significantly greater reductions in state positive affect, or increases in state negative affect, after the
$\mathrm{T}$ - compared to the $\mathrm{T}+$ treatment on either study day (see Table 2). Moreover, the reduced cooperation of those participants tested after the $\mathrm{T}$ - treatment on study day 1 cannot be attributed to an increase in state aggression in comparison with those tested after the $\mathrm{T}+$ treatment. These two groups of participants were matched on the multiple facets of aggression measured by the VAS (Bond and Lader, 1974) at baseline, and showed broadly similar changes during the interval between baseline and playing the PD game $+5 \mathrm{~h}$ later. At that time, 11 of the 13 VAS showed lower scores associated with the $\mathrm{T}-$ treatment compared to the $\mathrm{T}+$ treatment and only two showed higher scores (see Table 2). Indeed, the single significant treatment difference (uncorrected for multiple comparisons) at the time of playing the PD game on day 1 indicated that participants tested after the $\mathrm{T}$ - treatment rated themselves as significantly less rebellious than those tested after the $\mathrm{T}+$ treatment. In summary, there is no evidence to suggest that the reduced cooperation associated with the $\mathrm{T}-$ treatment on the first study day is explicable by differences in state affect, or increased state aggressivity, consequent to tryptophan depletion. Rather, the data indicate that serotonin can affect social cooperative behavior independently of the gross changes in emotional state that might be detectable by self-report measures of positive or negative affect including state aggression.

Similarly, those participants tested after the $\mathrm{T}-$ treatment and those tested after the $\mathrm{T}+$ treatment on the first study day also scored equivalently on trait positive and negative affect, as well as on self-report trait physical aggression, trait verbal aggression, trait anger, and trait hostility. Consequently, the reduced cooperation in the $\mathrm{PD}$ game associated with the $\mathrm{T}$ - treatment cannot be the result of between-subject variation in personality traits reflecting stable aspects of emotional function and aggression. (The two participant groups were also closely matched for age and estimated verbal IQ.) Accumulating data suggest that the effects of tryptophan depletion sometimes depend upon variation in associated traits linked to serotonergic function. Specifically, manipulation of $l$-tryptophan has been found to alter reactive aggression in participants with high, but not low, trait aggression (Cleare and Bond, 1995; Bjork et $a l, 2000)$ and in participants vulnerable to alcoholism (LeMarquand et al, 1999; Marsh et al, 2002). Such findings are consistent with evidence, cited above, that aggressive behavior depends upon serotonergic mechanisms in experimental, clinical, and naturalistic settings (Raleigh et al, 1991; Virkkunen et al, 1994; Giovanni et al, 2001 for a review). However, the present data also demonstrate an effect of tryptophan depletion on the acquisition of cooperative behavior in a laboratory measure of social cooperation that appears largely independent of variation in physical or verbal aspects of trait aggression, its (common) emotional correlate (anger), or the possession of critical social attitudes (as indexed by trait hostility).

One notable feature of our results is that there was a significant interaction between treatment and treatment order such that tryptophan depletion significantly affected performance of the PD game on the first but not the second study day. Similar interactions have been reported frequently in pharmacological studies of cognitive function that have used within-subject, crossover designs, including 
Table 2 Subjective Effects for Participants Who Drank an Amino-Acid Drink Containing I-Tryptophan $(T+)$ and Participants Who Drank an Amino-Acid Drink not Containing I-Tryptophan (T-) on Study Day I and Day 2

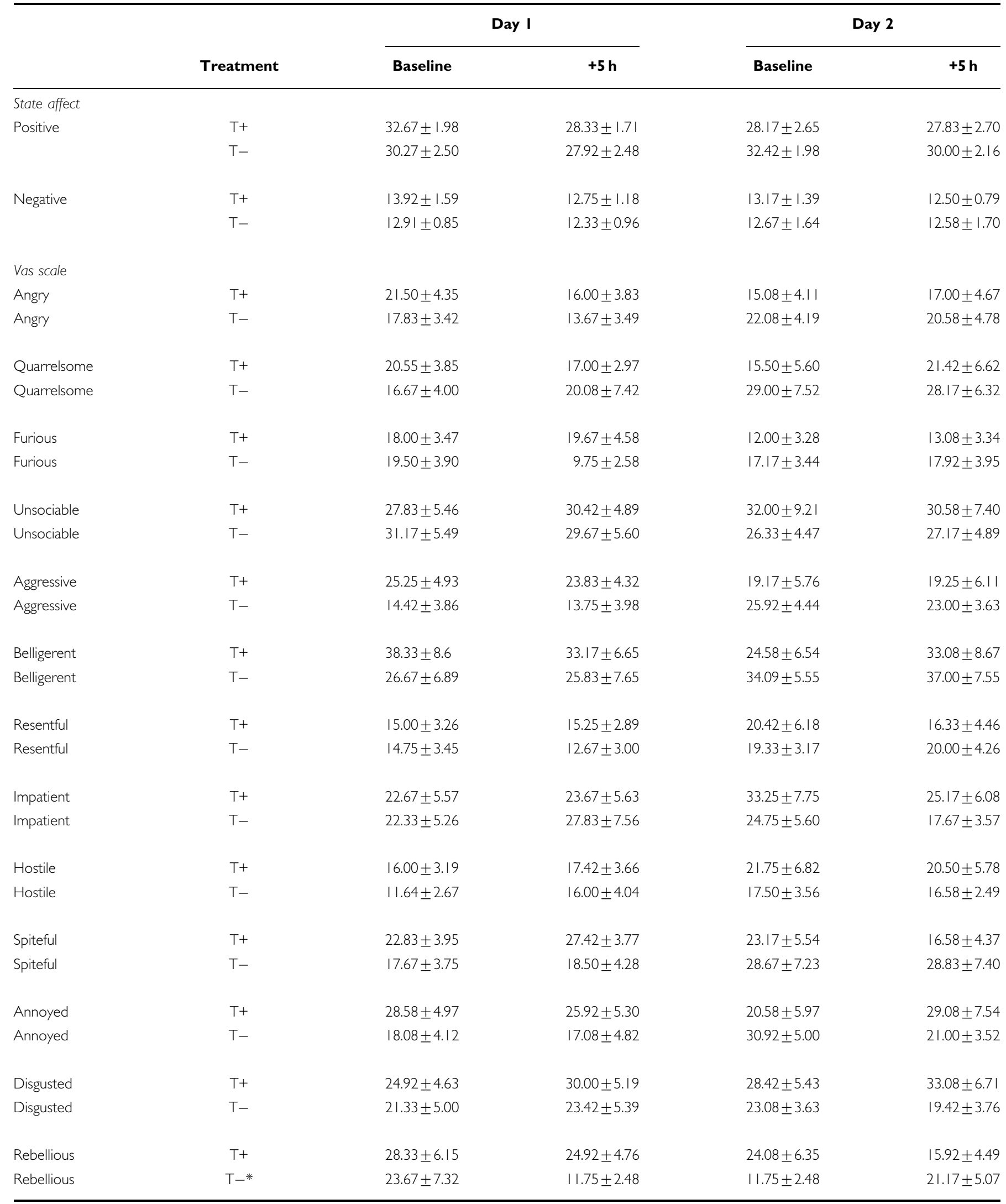

State positive and negative affect (PANAS). Visual analog scales for state aggression (VAS). ${ }^{*}=F(I, 20)=5.83, p<0.05$. 
some involving tryptophan depletion (Park et al, 1994). These effects reflect the fact that drug treatments can have different effects depending upon whether tasks are completed for the first or second time and are particularly marked where the tasks involve significant learning (Coull et al, 1995; Elliott et al, 1997). In the present study, analysis of the simple effects indicated that tryptophan depletion reduced participants' cooperative behavior on the first study day by approximately $31 \%$. This impression was reinforced by pair-wise comparisons indicating that participants who underwent the $\mathrm{T}$ - treatment on study day 1 , and who showed relatively reduced number of cooperative responses, significantly increased their cooperative responses after the $\mathrm{T}+$ treatment on study day 2 , while participants who underwent the $\mathrm{T}+$ treatment on day 1 showed similarly high levels of cooperation on day 2 . Evidence indicates that the tit-for-tat strategy followed by the fictional partner of the PD game in the present study (actually a prepared computer program) is highly effective in eliciting cooperation from other playing partners (Sheldon, 1999). Consequently, these data suggest that temporary disruption of serotonin impairs the acquisition of cooperative behaviors even when the strategies of social partners are geared to elicit reciprocal cooperation.

Serotonin has also been shown to influence learning mechanisms that may mediate acquisition of socially cooperative behavior (Fletcher et al, 1999; Sasaki-Adams and Kelley, 2001) and which depend upon much the same neural circuitry as performance of an iterated PD game (Rilling et al, 2002). Serotonergic depletions within the forebrain of monkeys (Clarke et al, 2004), and tryptophan depletion in humans (Park et al, 1994; Rogers et al, 1999), impair the ability to learn and relearn changing stimulusreinforcement associations, probably reflecting altered neuromodulation of circuitry encompassing the orbitofrontal cortex, cingulate cortex, and striatum (Cardinal et al, 2002). In the former study with healthy human participants (Park et al, 1994), tryptophan depletion also had a disproportionately greater impact on such associative learning on the first study day when participants completed the task for the first time. The capacity to link (and dynamically) relink stimuli to motivationally relevant outcomes is critical for effective function within social environments in which such linkages are apt to change rapidly and unpredictably (Rolls, 1996). Such conditions clearly obtained on study day 1 on which participants were required to assess the behavior of their partner and to adjust their own strategies in the light of varying outcomes from each round of the PD game. These conditions were less apparent on day 2 when participants repeated the task with the same fictional (confederate) and real (computer) partner.

These results shed light on the underlying role of serotonin in mediating social cooperation in healthy human participants, and highlight several directions for future research into this area, in addition to suggesting candidate neuropsychological mechanisms for social dysfunction in psychiatric disorder.

Brain-imaging studies have reported that mutual cooperative outcomes in the context of an iterated PD game of a kind similar to that played in this study was associated with increased BOLD signal within the rostral anterior cingulate cortex and anteroventral striatum compared to all other outcomes of the game (ie mixed cooperation/ defection and mutual defection). That data suggest that mutual cooperation activates neural systems of the forebrain, perhaps supporting the development of social reciprocity over repeated encounters (Rilling et al, 2002, 2004). Evidence has continued to accumulate suggesting that serotonin plays a significant role in modulating the reinforcement processes mediated by this circuitry and its mid-brain dopaminergic innervation. This evidence includes demonstrations that serotonergic activity enhances intracranial self-stimulation (Redgrave and Horrell, 1976) and that SSRI treatment decreases self-stimulation thresholds (Harrison and Markou, 2001). Additionally, potentiating and diminishing serotonergic activity has been found to increase and decrease the reinforcing effects of cocaine, respectively (Aronson et al, 1995; Sasaki-Adams and Kelley, 2001). Finally, Rogers et al (2003) recently demonstrated that tryptophan depletion altered healthy participants' processing of prospective gains, but not prospective losses or probability cues, when choosing between binaryoutcome gambles, suggesting that serotonin can, under appropriate conditions, modulate risky choice through the control of attention towards appetitive signals. Therefore, our finding that tryptophan depletion reduces cooperative choices on an iterated PD game of the kind employed in the present study suggests that serotonin modulates activity within circuitry encompassing the rostro-cingulate cortex and the striatum that mediates the reinforcing effects of cooperative behavior (Rilling et al, 2002). This hypothesis may provide a basis for understanding why major depressive disorder is associated with social withdrawal (see Fossi et al, 1984; Weissman, 2000) by positing a failure of serotonergic innervation to modulate appropriately the reinforcement value of social interactions (Libet and Lewinsohn, 1973; Youngren and Lewinsohn, 1980).

Additionally, it is notable that the reported effects were apparent in an iterated, sequential PD game in which the participants of the study made their choice about whether to cooperate or defect only after their playing partnerin fact, a computer playing a strict tit-for-tat strategyhad indicated his/her response. In this case, cooperative responses involved foregoing higher rewards available from a defection response (ie $30 \mathrm{p}$ ) in preference for smaller rewards available from mutually cooperative responses (ie 20p). Behavioral analyses of iterated PD games have shown that a player has two incompatible objectives in these circumstances (Raichlin et al, 2001). On the one hand, he/ she wishes to defect; on the other hand, he/she wishes to get his/her partner to cooperate. However, their partner's strict tit-for-tat strategy ensures that any defection will incur a retaliatory defection on the immediately following round of the game. At this point, the player will face a choice between becoming locked in an ongoing pattern of mutual defections or be forced to cooperate (while his partner defects) in order to re-establish a pattern of mutual cooperation. In this way, playing the iterated, sequential PD game, in which the partner plays strict tit-for-tat, involves the exercise of selfcontrol in forgoing the higher immediate reward produced by defecting when the partner has cooperated in favor of the immediately smaller (but cumulatively greater) rewards associated with enduring mutual cooperation. 
Consistent with work indicating that tit-for-tat strategies cooperative behavior (Axelrod, 1984; Sheldon, 1999), the T + treatment in the current study produced a clear preference for cooperation on both the first $(0.73 \pm 0.06)$ and second day $(0.64 \pm 0.09)$, suggesting that performance was supported by a strong representation of the longer-term benefits of mutual cooperation. Serotonin has frequently been associated with aspects of impulsivity in both clinical (Soubrie, 1986; Virkkunen et al, 1994) and experimental settings (Dalley et al, 2002), with demonstrations that tryptophan depletion can impair impulse control in healthy controls (Walderhaug et al, 2002) and in individuals with a family history of alcoholism (Crean et al, 2002; LeMarquand et al, 1999). Other data have suggested that depletion of central serotonin impairs the capacity to delay gratification (Denk et al, 2005; Mobini et al, 2000; Wogar et al, 1993). Consequently, the present findings suggest that tryptophan depletion significantly weakens the influence of the longerterm rewards associated with mutual cooperative strategies, perhaps represented within circuitry encompassing the orbitofrontal cortex (Bechara et al, 1996); thereby, undermining the basis for sustained reciprocation. This hypothesis may provide a basis for understanding how impulsiveness in personality disorders, associated with serotonergic dysfunction, undermines social function through an inadequate representation of the future reward-value of reciprocal cooperation. It also predicts that serotonergic manipulations will be most potent in determining social interactions, such as those involving tit-for-tat interactions, which pit immediate and delayed prospects for reinforcement against each other; by contrast, serotonergic manipulations in the context of other PD games involving other kinds of playing strategies may not produce such marked effects.

In summary, we have demonstrated that depriving healthy participants of $l$-tryptophan reduced cooperative behavior and the tendency of mutual cooperation to promote further cooperation. These results provide a starting point for testing novel hypotheses concerning the role of serotonin in social cooperation and its dysfunction in psychiatric disorders. These include (i) a failure to find cooperation with others adequately reinforcing and (ii) weakening the strength of long-term gains (associated with mutual cooperation) over short-term immediate rewards (associated with defection following cooperative responses by social partners).

\section{ACKNOWLEDGEMENTS}

This research was funded by an independent award from the Biotechnology and Biological Sciences Research Council (BBSRC; UK) to Robert D Rogers (S20137).

\section{REFERENCES}

Aronson S, Black J, McDougle C, Be S, Jatlow P, Heninger G et al (1995). Serotonergic mechanisms of cocaine effects in humans. Psychopharmacology 119: 179-185.

Axelrod R (1984). The Evolution of Cooperation. Penguin Books: New York.

Axelrod R, Hamilton WD (1981). The evolution of cooperation. Science 211: 1390-1396.
Bechara A, Tranel D, Damasio H, Damasio AR (1996). Failure to respond automatically to anticipated future outcomes following damage to prefrontal cortex. Cerebral Cortex 6: 215-225.

Biggio G, Fadda F, Fanni P, Tagliamonte A, Gessa G-L (1974). Rapid depletion of serum tryptophan, brain tryptophan, serotonin and 5-hyrdoxyindoleacetic acid by a tryptophan-free diet. Life Sci 14: 1321-1329.

Bjork JM, Dougherty DM, Moeller FG, Swann AC (2000). Differential behavioral effects of plasma tryptophan depletion and loading in aggressive and nonaggressive men. Neuropsychopharmacology 22: 357-369.

Bond A, Lader M (1974). The use of analogue scales in rating subjective feelings. Br J Med Psychol 47: 211-218.

Boone C, de Brabander B, Carree M, de Jong G, van Olffen W, van Witteloostuijn A (2002). Locus of control and learning to cooperate in a prisoner's dilemma game. Person Indiv Differ 32: 929-946.

Brown GL, Goodwin FK, Ballenger JC, Goyer PF, Major LF (1979). Aggression in humans correlates with cerebrospinal fluid amine metabolites. Psychiatry Res 1: 131-139.

Buss AP, Perry MP (1992). The aggression questionnaire. J Person Soc Psychol 63: 452-459.

Cardinal R, Parkinson J, Hall J, Everitt B (2002). Emotion and motivation: the role of the amygdala, ventral striatum, and prefrontal cortex. Neurosci Biobehav Rev 26: 321-352.

Carpenter LL, Anderson GM, Pelton GH, Gudin JA, Kirwin PDS, Price LH et al (1998). Tryptophan depletion during continuous CSF sampling in healthy human subjects. Neuropsychopharmacology 19: 26-35.

Clarke HF, Dalley JW, Crofts HS, Robbins TW, Roberts AC (2004). Cognitive inflexibility after prefrontal serotonin depletion. Science 304: 878-880.

Cleare AJ, Bond AJ (1995). The effect of tryptophan depletion and enhancement on subjective and behavioural aggression in normal male subjects. Psychopharmacology 118: 72-81.

Coccaro EF, Kavoussi RJ (1997). Fluoxetine and impulsive aggressive behavior in personality-disordered subjects. Arch Gen Psychiatry 54: 1081-1088.

Coull JT, Middleton HC, Robbins TW, Sahakian BJ (1995). Contrasting effects of clonidine and diazepam on tests of working memory and planning. Psychopharmacology 120: 311-321.

Crean J, Richards JB, de Wit H (2002). Effect of tryptophan depletion on impulsive behaviour in men with or without a family history of alcoholism. Behav Brain Res 136: 349-357.

Dalley JW, Theobald DE, Eagle DM, Passetti F, Robbins TW (2002). Deficits in impulse control associated with tonically-elevated serotonergic function in rat prefrontal cortex. Neuropsychopharmacology 26: 716-728.

Denk F, Walton ME, Jennings KA, Sharp T, Rushworth MF, Bannerman DM (2005). Differential involvement of serotonin and dopamine systems in cost-benefit decisions about delay or effort. Psychopharmacology 179: 587-596.

Dubini ABM, Polin V (1997). Do noradrenaline and serotonin differentially affect social motivation and behaviour? European Neuropsychopharmacology 7(Suppl 1): S49-S55.

Elliott R, Sahakian BJ, Matthews K, Bannerjea A, Rimmer J, Robbins TW (1997). Effects of methylphenidate on spatial working memory and planning in healthy young adults. Psychopharmacology 131: 105-111.

First MB, Spitzer RL, Gibbon M, Williams JBW (2002). Structured Clinical Interview for DSM-IV-TR Axis I Disorders, Research Version, Patient Edition. (SCID-I/P). Biometrics Research: New York.

Fletcher PJ, Korth KM, Chambers JW (1999). Selective destruction of brain serotonin neurons by 5,7-dihydroxytryptamine increases responding for a conditioned reward. Psychopharmacology 147: 291-299.

Fossi L, Faravelli C, Paoli M (1984). The ethological approach to the assessment of depressive disorders. J Nerv Ment Dis 172: 332-341. 
Fuller RW (1996). The influence of fluoxetine on aggressive behavior. Neuropsychopharmacology 14: 77-81.

Giovanni PA, Placidi MA, Oquendo MA, Malone KM, Huang YY, Ellis SP et al (2001). Aggressivity, suicide attempts, and depression: relationship to cerebrospinal fluid monoamine metabolite levels. Biol Psychiatry 50: 783-791.

Harrison A, Markou A (2001). Serotonergic manipulations both potentiate and reduce brain stimulation reward in rats: involvement of serotonin-1A receptors. J Pharmacol Exp Ther 297: 316-325.

Higley JD, Mehlman PT, Poland RE, Taub DM, Higley SB, Suomi SJ et al (1992). Cerebrospinal fluid monoamine and adrenal correlates of aggression in free-ranging rhesus monkeys. Arch Gen Psychiatry 49: 436-441.

Higley JD, Mehlman PT, Poland RE, Taub DM, Vickers J, Suomi SJ et al (1996). CSF testosterone and 5-HIAA correlate with different types of aggressive behaviors. Biol Psychiatry 40: 1067-1082.

Knutson B, Panksepp J (1996). Effects of fluoxetine on play dominance in juvenile rats. Aggress Behav 22: 297-307.

Knutson B, Wolkowitz OW, Cole SW, Chan T, Moore EA, Johnson RC et al (1998). Selective alteration of personality and social behaviour by serotonergic intervention. Am J Psychiatry 155: 373-379.

LeMarquand DG, Benkelfat C, Pihl RO, Palmour RM, Young SN (1999). Behavioral disinhibition induced by tryptophan depletion in nonalcoholic young men with multigenerational family histories of paternal alcoholism. Am J Psychiatry 156: 1771-1779.

Libet J, Lewinsohn PM (1973). The concept of social skill with special references to the behaviour of depressed persons. J Consult Clin Psychol 40: 304-312.

Marsh DM, Dougherty DM, Moeller FG, Swann AC, Spiga R (2002). Laboratory-measured aggressive behavior of women: acute tryptophan depletion and augmentation. Neuropsychopharmacology 26: 660-671.

Mobini S, Chiang TJ, Ho MY, Bradshaw C, Szabadi E (2000). Effects of central 5-hydroxytryptamine depletion on sensitivity to delayed and probabilistic reinforcement. Psychopharmacology 152: 390-397.

Moore P, Hans-Peter L, Seifritz E, Clark C, Bhatti T, Kelsoe J et al (2000). Clinical and physiological consequences of rapid tryptophan depletion. Neuropsychopharmacology 23: 601-622.

Moskowitz DS, Cote S (1995). Do interpersonal traits predict affect? A comparison of three models. J Person Soc Psychol 69: 915-924.

Moskowitz DS, Pinard G, Zuroff DC, Annable L, Young SN (2001). The effect of tryptophan on social interaction in everyday life: a placebo-controlled study. Neuropsychopharmacology 25: 277-289.

Nelson HE (1982). National Adult Reading Test (NART) Test Manual. NFER-Nelson: Windsor (UK).

Park SB, Coul JT, McShane RH, Young AH, Sahakian BJ, Robbins TW et al (1994). Tryptophan depletion in normal participants produces selective impairments in learning and memory. Neuropharmacology 33: 575-588.

Pruitt D, Kimmel M (1977). Twenty years of experimental gaming: critique, synthesis, and suggestions for the future. Annu Rev Psychol 28: 363-392.

Raichlin H, Brown J, Baker F (2001). Reinforcement and punishment in the Prisoner's Dilemma game. Psychol Learn Motiv 40: 327-364.

Raleigh MJ, Brammer GL, McGuire MT, Yuwiler A (1985). Dominant social status facilitates the behavioral effects of serotonergic agonists. Brain Res 348: 274-282.

Raleigh MJ, McGuire MT, Brammer GL, Pollack DB, Yuwiler A (1991). Serotonergic mechanisms promote dominance acquisition in adult male monkeys. Brain Res 559: 181-190.

Raleigh MJ, Yuwiler A, Brammer GL, McGuire MT, Geller E, Flannery JW (1981). Peripheral correlates of serotonergically- influenced behaviors in vervet monkeys (Cercopithecus aethiops sabaeus). Psychopharmacology 72: 241-246.

Redgrave P, Horrell RI (1976). Potentiation of central reward by localised perfusion of acetylcholine and 5-hydroxytryptamine. Nature 262: 305-307.

Rilling JK, Gutman DA, Zeh TR, Guiseppe P, Berns GS, Kilts CD (2002). A neural basis for social cooperation. Neuron 35: 395-405.

Rilling JK, Sanfey AG, Aronson JA, Nystrom LE, Cohen JD (2004). The neural correlates of theory of mind within interpersonal interactions. Neuroimage 22: 1694-1703.

Robbins TW, Cador M, Taylor J, Everitt B (1989). Limbic-striatal interactions in reward-related processes. Neurosci Biobehav Rev 13: $155-162$.

Robbins TW, Everitt BJ (1996). Neurobehavioural mechanisms of reward and motivation. Curr Opin Neurobiol 6: 228-236.

Rogers RD, Blackshaw AJ, Middleton HC, Matthews K, Deakin JFW, Sahakian BJ et al (1999). Tryptophan depletion impairs stimulus-reward learning while methylphenidate disrupts attentional control in healthy young adults: implications for the monoaminergic basis of impulsive behaviour. Psychopharmacology 146: 482-491.

Rogers RD, Tunbridge EM, Bhagwagar Z, Drevets W, Sahakian BJ, Carter CS (2003). Tryptophan depletion alters the decisionmaking of healthy participants through altered processing of reward cues. Neuropsychopharmacology 28: 153-162.

Rolls ET (1996). The orbitofrontal cortex. Philos Trans Roy Soc London (Series B) 351: 1433-1444.

Sasaki-Adams DM, Kelley AE (2001). Serotonin-dopamine interactions in the control of conditioned reinforcement and motor behavior. Neuropsychopharmacology 25: 440-452.

Sheldon KM (1999). Learning the lessons of tit-for-tat: even competitors can get the message. J Person Soc Psychol 77: $1245-1253$

Soubrie P (1986). Reconciling the role of serotonin neurons in human and animal behaviour. Behav Brain Sci 9: 319-362.

Trivers R (1971). The Evolution of Reciprocal Altruism. Q Rev Biol 46: 35-37.

Trivers R (1985). Social Evolution. Benjamin/Cummings: Menlo Park, Cambridge, CA.

Tse WS, Bond AJ (2002a). Serotonergic intervention affects both social dominance and affiliative behaviour. Psychopharmacology 161: 324-330.

Tse WS, Bond AJ (2002b). Differences in serotonergic and noradrenergic regulation of human social behaviours. Psychopharmacology 159: 216-221.

Virkkunen M, Rawlings R, Tokola R, Poland RE, Guidotti A, Nemeroff C et al (1994). CSF biochemistries, glucose metabolism, and diurnal activity rhythms in alcoholic, violent offenders, fire setters, and healthy participants. Arch Gen Psychiatry 51: 20-27.

Walderhaug E, Lunde H, Nordvik JE, Landro NI, Refsum H, Magnusson A (2002). Lowering of serotonin by rapid tryptophan depletion increases impulsiveness in normal individuals. Psychopharmacology 164: 385-391.

Watson D, Clark LA, Tellegen A (1988). Development and validation of brief measures of positive and negative affect: The PANAS scales. J Person Soc Psychol 54: 1063-1070.

Weissman MM (2000). Social functioning and the treatment of depression. J Clin Psychiatry 61(Suppl 1): 33-38.

Wogar MA, Bradshaw CM, Szabadi E (1993). Effect of lesion of the ascending 5-hydroxytryptaminergic pathways on choice between delayed reinforcers. Psychopharmacology 111: 239-243.

Youngren MA, Lewinsohn PM (1980). The functional relation between depression and problematic interpersonal behavior. J Abnormal Psychol 89: 333-341. 